\title{
Efficacy research of salazosulfamide in ankylosing spondylitis and NAT1 gene polymorphism
}

\author{
XIU-FEN MA, XIAO-DONG WANG, RUN-RONG LIU and QING-XIA LUAN \\ Division of Immunology and Rheumatology, Affiliated Hospital \\ of Weifang Medical University, Weifang, Shandong 261031, P.R. China
}

Received August 31, 2016; Accepted April 3, 2017

DOI: $10.3892 /$ etm.2017.4844

\begin{abstract}
The aim of this study was to explore the correlation of salazosulfamide efficacy on ankylosing spondylitis and $\mathrm{N}$-acetyltransferase 1 (NAT1) gene polymorphism. Thirty-two patients with ankylosing spondylitis were recruited in the experimental group and 36 normal individuals were recruited to the control group. The experimental group received $8.0 \mathrm{mg}$ of salazosulfamide (MTX) per week and the control group received isodose of normal saline. Twenty-six patients in the experimental group responded to the salazosulfamide treatment and 6 did not show response. Morning stiffness time of patients in the experimental group who responded to salazosulfamide was significantly lower than that of patients with no reaction to salazosulfamide, and similar to patients in the control group. The average tender joint count of patients in the experimental group that responded to salazosulfamide was lower than in patients with no response to treatment, and similar to patients in the control group. NAT1 gene sequencing determined that the patients sensitive to salazosulfamide treatment manifested as AA/AG at 263 locus, whereas patients not sensitive to salazosulfamide were GG. NAT1 expression was comparable between the different genotypes at the mRNA level. However, there was a significant difference of NAT1 protein between groups. Overall, salazosulfamide demonstrates curative activity for ankylosing spondylitis and we believe that NAT1 AA/GG genotype at 263 locus can promote salazosulfamide effectiveness on ankylosing spondylitis.
\end{abstract}

\section{Introduction}

Ankylosing spondylitis (AS) is a spinal disease condition that manifests as sacroiliac joint and spine attachment point inflammation that can cause spine fibrosis and poker spine,

Correspondence to: Dr Xiu-Fen Ma, Division of Immunology and Rheumatology, Affiliated Hospital of Weifang Medical University, 2428 Yuhe Road, Weifang, Shandong 261031, P.R. China

E-mail: hvnt16925444894@163.com

Key words: salazosulfamide, ankylosing spondylitis, $\mathrm{N}$-acetyltransferase 1 , gene polymorphism correlation leading to damage of muscle, skeleton, and lung function (1). The morbidity rates of ankylosing spondylitis in Asia China are 0.89 and $1.83 \%$, respectively (2). Ankylosing spondylitis affects mainly young adults aged 24-43 years, and is a cause of major loss for both family and society (3). Although ankylosing spondylitis research has drawn attention in recent years (4), the pathogenesis of ankylosing spondylitis is not clear so far. The morbidity of ankylosing spondylitis is proposed to be related to environmental and genetic factors (5). For instance, the incidence of ankylosing spondylitis in people who do manual work or stand for a long period of time is higher than that for the general population. As an important enzyme of acetylated metabolism in humans, $\mathrm{N}$-acetyltransferase 1 (NAT1) provides nutrients for normal growth and development of organism osteoblast (6), and can also degrade carcinogens and teratogens, to maintain a steady state within the organism (7).

In this study, we observed the therapeutic effect of salazosulfamide on patients with ankylosing spondylitis and sequenced NAT1 gene. We found a strong correlation between salazosulfamide efficacy in ankylosing spondylitis and NATI polymorphism, which provides theoretical and experimental basis for the treatment of ankylosing spondylitis.

\section{Materials and methods}

Subject data. We recruited 32 patients with ankylosing spondylitis who were admitted to our hospital from February 2014 to February 2015 as the experimental group. Of the 32 patients, 18 were male and 14 female, with an average age of $32.4 \pm 12.6$ years. We also recruited 36 normal individuals as the control group, which contained 20 males and 16 females, with an average age of $33.7 \pm 11.8$ years.

Methods. The experimental group received $7.5 \mathrm{mg}$ of salazosulfamide (MTX) per week and the control group received an isodose of normal saline. We measured morning stiffness time and tender joint count measured at weeks 4, 8, 12, 16, 20, 24 and 26 post-treatment. Five milliliters of elbow venous blood was collected, centrifuged at 2,650 x g for $5 \mathrm{~min}$, cryopreserved solution was added, and the supernatant was stored at $-80^{\circ} \mathrm{C}$ for follow-up tests.

Genomic extraction. DNA was extracted from the blood of the two groups using the DNA extraction kit of Qiagen 
Table I. Primer sequences.

\begin{tabular}{lc}
\hline Primer & Sequence \\
\hline nat-F & GTCGATGCTAGCTACGGCTAG \\
nat-R & GTCGATCGGCTAGCTAGAAGC
\end{tabular}

F, forward; R, reverse.

Table II. PCR fluorescent quantitation primer.

\begin{tabular}{ll}
\hline Primer & \multicolumn{1}{c}{ Sequence } \\
\hline nat-F & AGTCGATGCTAGCTGATCGC \\
nat-R & CGTAGCTGCTAGCTAGCTAG \\
GAPDH-F & TGACTTCAACAGCGACACCCA \\
GAPDH-R & CACCCTGTTGCTGTAGCCAAA \\
\hline
\end{tabular}

F, forward; R, reverse.

(Hilden, Germany) and DNA concentration was measured by micro-ultraviolet-visible spectrophotometer.

Genotype. PCR-SSP kit was used to determine the NATI genotypes of the patients. The primers were obtained from Shanghai Bioengineering (Shanghai, China) (Table I). The genotype of the common NATl polymorphisms was obtained by different primers, then PCR products were heated to $95^{\circ} \mathrm{C}$ in a GeneAmp PCR for denaturation, and added to the nylon membrane that was marked by specificity nucleotide fragment probe in advance. Through complementation, single-strand DNA and specific fragments hybridized, then horseradish peroxidase (HRP)-labeled with streptomycin was added for 2 min with mixed tetramethyl benzidine and $\mathrm{H}_{2} \mathrm{O}_{2}$ for chromogenic reaction. Then, we developed coloration in the nylon membrane by Vilber Lourmat (Bio-Rad Laboratories, Inc., Hercules, CA, USA), and NAT1 polymorphisms were distinguished by hybridizing bands.

RNA extraction and quantitative PCR (8). Samples $(0.25 \mathrm{~g})$ were placed on ice. Then, $0.4 \mathrm{ml}$ of RNA Plus (Takara Bio) was added and samples were grinded quickly in precooled mortar. RNase inhibitor was added to the $1.5 \mathrm{ml}$ tubes, and $0.15 \mathrm{ml}$ of RNA Plus was used to rewash the mortar, which was transferred to a centrifuge tube after washed. Three hundred fifty mircoliters of chloroform was added to the tube, with quick shaking for $15 \mathrm{sec}$, incubated for $15 \mathrm{~min}$ and centrifuged at $10,050 \mathrm{xg}$ at $4^{\circ} \mathrm{C}$ for 15 min (Bio-Rad Laboratories, Inc.). The supernatant was transferred to a tube without RNase, and equivalent isopropanol volume was added, rapidly inverted to mix, incubated for $10 \mathrm{~min}$ and centrifuged at $10,050 \mathrm{xg}$ at $4^{\circ} \mathrm{C}$ for $10 \mathrm{~min}$. The supernatant was removed and $1,000 \mu \mathrm{l}$ of $75 \%$ ethanol was added, with gentle mixing and centrifuging at $10,050 \mathrm{xg}$ at $4^{\circ} \mathrm{C}$ for $10 \mathrm{~min}$. The supernatant was collected and ethanol was cleared. RNase water was added to determine RNA quality.

Fluorescent quantitation inverse transcription and quantitative experiment were conducted following Takara Bio (Dalian,
China) instructions using the fluorescent quantitative reaction system: $5 \mu$ l SYBR Premix Ex Taq II (2X), $0.5 \mu \mathrm{l}$ PCR forward primer $(10 \mu \mathrm{M}), 0.5 \mu \mathrm{l}$ PCR reverse primer $(10 \mu \mathrm{M}), 1 \mu \mathrm{l}$ cDNA and $3 \mu 1 \mathrm{dH}_{2} \mathrm{O}$. (The primer sequence shown in Tables II and III).

Enzyme-linked immunosorbent assay (ELISA) (9). Total protein $(10-20 \mu \mathrm{g})$ was extracted from serum from all the subjects to measure NAT1 protein expression following the instructions of the ELISA kit (Qiagen). The standard protein sample for the ELISA standard curve was diluted at 1:100 by elution buffer, and the standard curve was created according to the instruction. After dilution at 1:200 in sterilized PBS (pH 7.2), $100 \mu 1$ solution was added to 96-well plates, and $50 \mu 1$ detection solution was added to each plate. After incubation at room temperature for $2 \mathrm{~h}$, TMB chromogenic substrate was added. Light absorption was measured at $495 \mathrm{~nm}$ and NAT1 protein concentration in the samples was calculated according to the standard curve.

Western blotting. For western blotting, we followed the instructions in Molecular Cloning, third version. Mouse monoclonal HLA primary antibody (cat. no. MA5-11723; Thermo Fisher Scientific, Waltham, MA, USA), and SO-HLA genotype kit (Dynal Biotech Ltd., Wirral, UK) were also used.

Measurement of morning stiffness time. To measure morning stiffness, we followed the procedures described by Jansen et al (10).

Measurement of tender joint count. To measure tender joint count, we followed the procedures described by Arends et al (11).

Statistical analysis. We used software SPSS 20.0 (IBM SPSS, Armonk, NY, USA) to analyze the data. Experiment data was presented by mean \pm standard deviation (mean $\pm \mathrm{SD}$ ). Single factor method was conducted for statistical analysis of different groups. $\mathrm{P}<0.05$ meant that the difference had statistical significance.

\section{Results}

Morning stiffness time. We analyzed morning stiffness time for the control and the experimental groups. A fraction of the patients in the experimental group demonstrated response to salazosulfamide (Fig. 1). These responsive patients demonstrated low morning stiffness time $(4.03 \mathrm{~min})$ that was comparable to the control group $(2.83 \mathrm{~min})$. However, the salazosulfamide non-responsive patients in the experimental group exhibited high morning stiffness time $(36.7 \mathrm{~min})$ that was significantly higher than the salazosulfamide responsive and control patients (Fig. 1).

Tender joint count. We next measured tender joint count in both groups. The salazosulfamide responsive patients from the experimental group showed a tender joint count of 0.3 , which was similar to the result for the control group (0.24) (Fig. 2). However, the salazosulfamide non-responsive patients had a tender joint count of 2.41 , which was significantly higher than that of the control group and the salazosulfamide responsive patients (Fig. 2). 
Table III. Statistics of HLA-A allelomorph and gene frequency.

\begin{tabular}{|c|c|c|c|c|c|c|c|}
\hline \multirow[b]{3}{*}{ Nat } & \multicolumn{3}{|c|}{ Observation (32 patients) } & \multicolumn{3}{|c|}{ Control (36 patients) } & \multirow[b]{3}{*}{$\chi^{2}$} \\
\hline & \multicolumn{3}{|c|}{ Sensitive to salazosulfamide } & \multicolumn{3}{|c|}{ Insensitive to salazosulfamide } & \\
\hline & Cases & Frequency $(\%)$ & Cases & Frequency $(\%)$ & Cases & Frequency $(\%)$ & \\
\hline AA & 15 & 57.7 & 0 & 0 & 1 & 2.8 & 6.04 \\
\hline AG & 11 & 42.3 & 0 & 0 & 3 & 8.3 & 0.12 \\
\hline GG & 0 & 0 & 6 & 100 & 32 & 88.9 & 0.18 \\
\hline
\end{tabular}

$\mathrm{P}<0.05$ means that the difference has statistical significance.

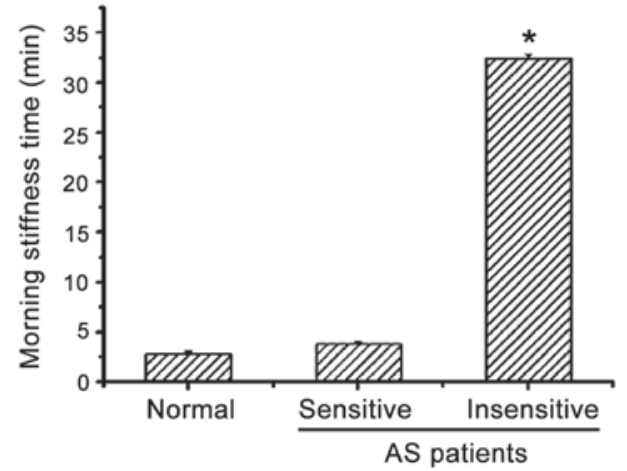

Figure 1. Morning stiffness time. Asterisk indicates statistically significant differences between groups.

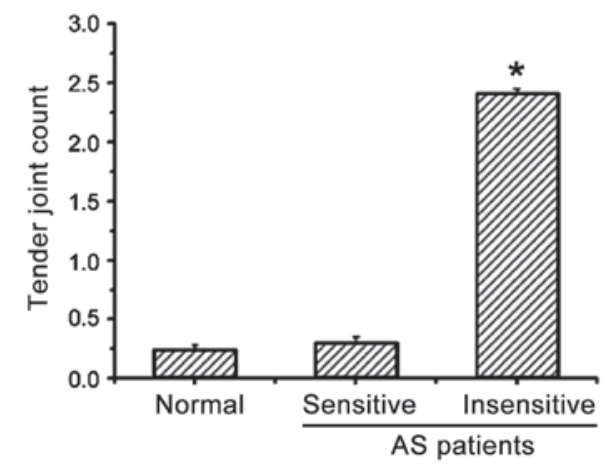

Figure 2. Tender joint count. Asterisk indicates statistically significant differences between groups.

NAT1 gene polymorphisms. To determine the role of NAT1 in the response to salazosulfamide, we sequenced the NATI gene sequencing to determine the distribution of known polymorphisms. Twenty-six patients sensitive to salazosulfamide contained AA (57\%) and AG (42.3\%) at locus 263. Six patients insensitive to salazosulfamide were GG genotype $(88.9 \%)$ at locus 263, with a small frequency of AA (2.8\%) and AG (8.3\%). These results suggested that NAT1 polymorphism distribution strongly correlated with salazosulfamide sensitivity in ankylosing spondylitis.

NAT1 mRNA expression. To determine whether the NAT1 polymorphisms affect mRNA expression, we quantified mRNA from our patients. We found that the expression of

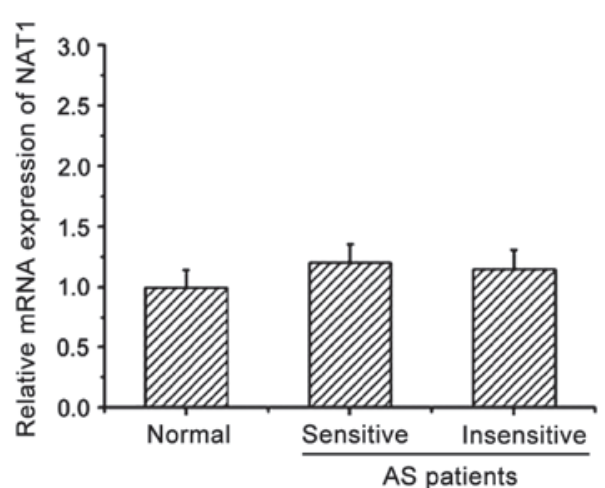

Figure 3. NAT1 mRNA expression in different groups. NAT1, N-acetyltransferase 1.

NAT1 mRNA was comparable between the control group, and salazosulfamide responsive and non-responsive in the experimental group (Fig. 3).

NAT1 protein expression: ELISA. We then determined the levels of NAT1 protein expression from all the groups by ELISA to determine if the polymorphisms could affect protein expression or stability. The expression of NAT1 protein in salazosulfamide responsive patients $(1.63 \pm 0.12 \mu \mathrm{g} / \mathrm{l})$ was comparable to the expression in the control group $(1.4 \pm 0.1 \mu \mathrm{g} / \mathrm{l})$ (Fig. 4). However, the expression of NAT1 in the salazosulfamide non-responsive patients was much lower $(0.26 \pm 0.04 \mu \mathrm{g} / \mathrm{l})$ than in the salazosulfamide responsive and the control patients (Fig. 4).

NAT1 protein expression: Western blotting. To confirm the ELISA results with a different technique, we measured NAT1 expression by western blotting. The expression of NAT1 protein in the salazosulfamide responsive patients in the experimental group was comparable to the levels in control patients (Fig. 5). However, NAT1 protein expression in salazosulfamide non-responsive patients decreased significantly (Fig. 5). These results are consistent with the ELISA results described above.

\section{Discussion}

The incidence of ankylosing spondylitis is closely associated with environmental factors, such as living style, dietary habits, and genetic factors (12). As a systemic autoimmune disease, 


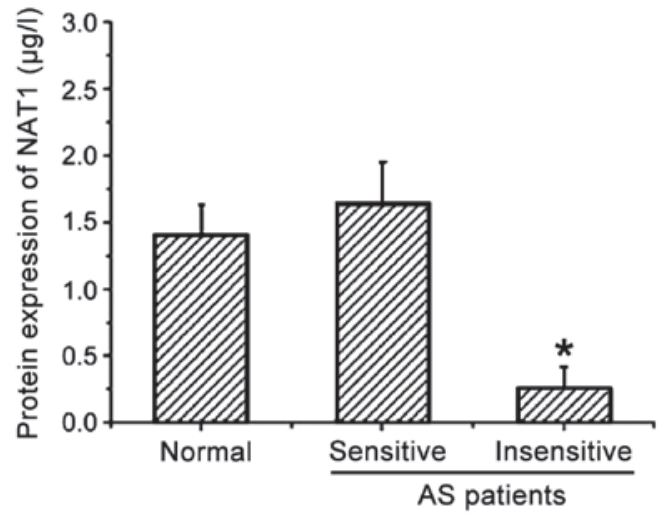

Figure 4. NAT1 protein expression in different groups by ELISA. Asterisk indicates statistically significant differences between groups. NAT1, $\mathrm{N}$-acetyltransferase 1; ELISA, enzyme-linked immunosorbent assay.

A

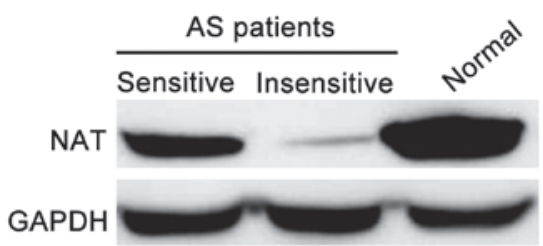

B

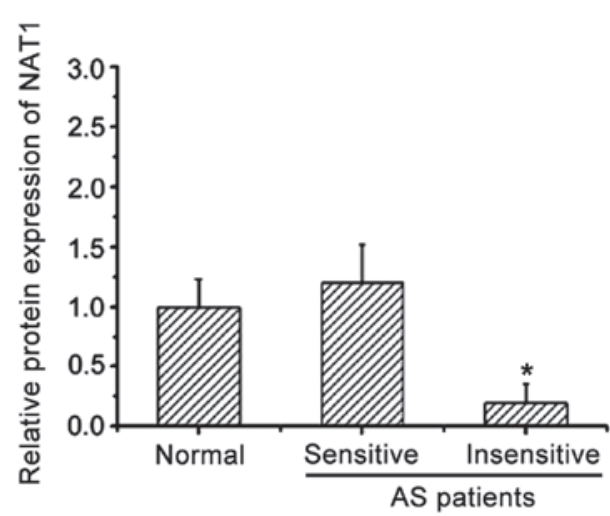

Figure 5. NAT1 protein expression in different groups by western blotting (A) Western blotting qualitative result. (B) Western blotting quantitative result. Asterisk indicates statistically significant differences between groups. NAT1, N-acetyltransferase 1.

ankylosing spondylitis can cause infection due to decreasing immunocompetence. Salazosulfamide can improve pain and the development of ankylosing spondylitis, and decrease IgA level in serum (13), which is appropriate for improving peripheral articular synovial inflammation of patients with ankylosing spondylitis. However, the clinical efficacy of salazosulfamide is not obvious in different populations. In recent years, it was found that ankylosing spondylitis is associated with imbalance of immune function (14). For example, the critical immunoregulator Th17 cells plays a significant regulating role in the mediation of inflammatory reaction and autoimmune disease (15). The number of Th17 cells in patients with ankylosing spondylitis was significantly decreased compared with normal individuals, but the reason was not clear (16). Salazosulfamide is widely used in the treatment of ankylosing spondylitis (17); however, clinical data showed that salazosulfamide is not effective in all patients (2). Previous findings showed that the NATl gene is highly polymorphic (18), and over 26 NAT1 polymorphisms have been described. NAT1 is a xenobiotic metabolizing enzyme mainly involved in substrate acetylation, a main route of modifying gap-associated proteins, and the function of the protein modified by acetylation changes correspondingly (19).

In the present study, we found that salazosulfamide efficacy for the treatment of ankylosing spondylitis is associated with NAT1 polymorphisms. However, we did not study the mechanisms mediating the role of NATl polymorphism on salazosulfamide effectiveness in ankylosing spondylitis. Future studies should be conducted to investigate these issues.

\section{References}

1. Mikuls TR, Levan T, Gould KA, Yu F, Thiele GM, Bynote KK, Conn D, Jonas BL, Callahan LF, Smith E, et al: Impact of interactions of cigarette smoking with NAT2 polymorphisms on rheumatoid arthritis risk in African Americans. Arthritis Rheum 64: 655-664, 2012.

2. Zhang J, Qiu LX, Wang ZH, Wang JL, He SS and Hu XC: NAT2 polymorphisms combining with smoking associated with breast cancer susceptibility: a meta-analysis. Breast Cancer Res Treat 123: 877-883, 2010.

3. Poddubnyy D, Haibel H, Listing J, Märker-Hermann E, Zeidler H, Braun J, Sieper J and Rudwaleit M: Baseline radiographic damage, elevated acute-phase reactant levels, and cigarette smoking status predict spinal radiographic progression in early axial spondylarthritis. Arthritis Rheum 64: 1388-1398, 2012.

4. Canbaz D, Utsch L, Logiantara A, van Ree R and van Rijt LS: IL-33 promotes the induction of immunoglobulin production after inhalation of house dust mite extract in mice. Allergy 70: 522-532, 2015.

5. Huang F, Gu J, Liu Y, Zhu P, Zheng Y, Fu J, Pan S and Le S: Efficacy and safety of celecoxib in chinese patients with ankylosing spondylitis: a 6-week randomized, double-blinded study with 6-week open-label extension treatment. Curr Ther Res Clin Exp 76: 126-133, 2014.

6. Chang SH, Choi BY, Choi J, Yoo JJ, Ha YJ, Cho HJ, Kang EH, Song YW and Lee YJ: Baseline serum interleukin-34 levels independently predict radiographic progression in patients with rheumatoid arthritis. Rheumatol Int 35: 71-79, 2015.

7. Kadi A, Costantino F, Izac B, Leboime A, Said-Nahal R, Garchon HJ, Chiocchia G and Breban M: Brief report: the IL23R nonsynonymous polymorphism rs11209026 is associated with radiographic sacroiliitis in spondyloarthritis. Arthritis Rheum 65: 2655-2660, 2013.

8. Khan MA: Polymorphism of HLA-B27: 105 subtypes currently known. Curr Rheumatol Rep 15: 362, 2013.

9. Yan JW, Wang YJ, Peng WJ, Tao JH, Wan YN, Li BZ, Mei B, Chen B, Yao H, Yang GJ, et al: Therapeutic potential of interleukin-17 in inflammation and autoimmune diseases. Expert Opin Ther Targets 18: 29-41, 2014.

10. Jansen DT, Hameetman M, van Bergen J, Huizinga TWJ, van der Heijde D, Toes REM and van Gaalen FA: IL-17-producing $\mathrm{CD} 4^{+} \mathrm{T}$ cells are increased in early, active axial spondyloarthritis including patients without imaging abnormalities. Rheumatology (Oxford) 54: 728-735, 2015.

11. Arends S, Brouwer E, van der Veer E, Groen H, Leijsma MK, Houtman PM, Th A Jansen TL, Kallenberg CG and Spoorenberg A: Baseline predictors of response and discontinuation of tumor necrosis factor-alpha blocking therapy in ankylosing spondylitis: a prospective longitudinal observational cohort study. Arthritis Res Ther 13: R94, 2011.

12. Glintborg B, Ostergaard M, Krogh NS, Dreyer L, Kristensen HL and Hetland ML: Predictors of treatment response and drug continuation in 842 patients with ankylosing spondylitis treated with anti-tumour necrosis factor: results from 8 years surveillance in the Danish nationwide DANBIO registry. Ann Rheum Dis 69: 2002-2008, 2010.

13. Cox DG, Dostal L, Hunter DJ, Le Marchand L, Hoover R, Ziegler RG, Thun MJ, Diver WR, Stevens VL, Amiano P, et al; Breast and Prostate Cancer Cohort Consortium: N-acetyltransferase 2 polymorphisms, tobacco smoking, and breast cancer risk in the breast and prostate cancer cohort consortium. Am J Epidemiol 174: 1316-1322, 2011. 
14. Anderson LN, Cotterchio M, Mirea L, Ozcelik H and Kreiger N: Passive cigarette smoke exposure during various periods of life, genetic variants, and breast cancer risk among never smokers. Am J Epidemiol 175: 289-301, 2012.

15. Fircanis S, Merriam P, Khan N and Castillo JJ: The relation between cigarette smoking and risk of acute myeloid leukemia: an updated meta-analysis of epidemiological studies. Am J Hematol 89: E125-E132, 2014.

16. Sim E, Fakis G, Laurieri N and Boukouvala S: Arylamine N-acetyltransferases - from drug metabolism and pharmacogenetics to identification of novel targets for pharmacological intervention. Adv Pharmacol 63: 169-205, 2012.
17. Mortensen HM, Froment A, Lema G, Bodo JM, Ibrahim M, Nyambo TB, Omar SA and Tishkoff SA: Characterization of genetic variation and natural selection at the arylamine $\mathrm{N}$-acetyltransferase genes in global human populations. Pharmacogenomics 12: 1545-1558, 2011.

18. Rota M, Porta L, Pelucchi C, Negri E, Bagnardi V, Bellocco R, Corrao G, Boffetta P and La Vecchia C: Alcohol drinking and risk of leukemia-a systematic review and meta-analysis of the dose-risk relation. Cancer Epidemiol 38: 339-345, 2014.

19. da Silva TD, Felipe AV, de Lima JM, Oshima CT and Forones NM: N-Acetyltransferase 2 genetic polymorphisms and risk of colorectal cancer. World J Gastroenterol 17: 760-765, 2011. 